\title{
Comprehensive study on hybrid anaerobic reactor built-in with sleeve type bioelectrocatalyzed modules
}

\author{
Dan Cui ${ }^{\mathrm{a}, \mathrm{b}}$, Min-Hua Cui ${ }^{\mathrm{c}}$, Hyung-Sool Lee ${ }^{\mathrm{d}}$, Bin Liang ${ }^{\mathrm{b}}$, Hong-Cheng Wang ${ }^{\mathrm{b}}$, Wei-Wei Cai ${ }^{\mathrm{c}}$, \\ Hao-Yi Cheng ${ }^{\mathrm{b}}$, Xu-Liang Zhuang ${ }^{\mathrm{b}, *}$, Ai-Jie Wang ${ }^{\mathrm{b}, \mathrm{c}, *}$ \\ a National Engineering Laboratory for Advanced Municipal Wastewater Treatment and Reuse Technology, Beijing University of Technology, Beijing 100124, China \\ ${ }^{\mathrm{b}}$ Key Laboratory of Environmental Biotechnology, Research Center for Eco-Environmental Sciences, Chinese Academy of Sciences, Beijing 100085 , PR China \\ ' State Key Laboratory of Urban Water Resource and Environment, Harbin Institute of Technology, Harbin 150090, PR China \\ d Department of Civil and Environmental Engineering, University of Waterloo, 200 University Avenue West Waterloo, Ontario N2L 3G1, Canada
}

\section{G R A P H I C A L A B S T R A C T}

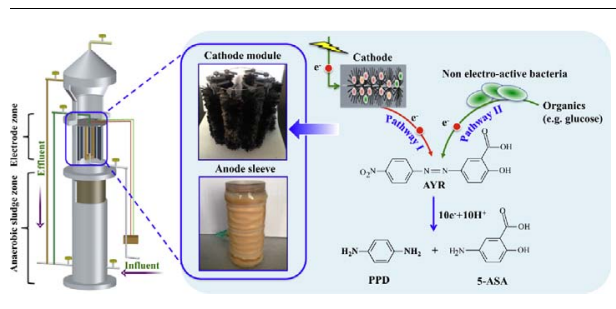

\section{A R T I C L E I N F O}

\section{Keywords:}

Hybrid anaerobic reactor

BES

Azo dye

Microbial community

Hydrodynamic

\begin{abstract}
A B S T R A C T
The successful application of bio-electrocatalyzed system (BES) to wastewater treatment inevitably depends on the improvement of performance and the reduction of costs at a scale-up level. One efficient way to achieve these goals is to couple BES with traditional anaerobic processes to industrial wastewater treatment. Here we developed a hybrid anaerobic system built-in with electrode modules (HAR-BES, $30 \mathrm{~L}$ ) as an inexpensive but highperformance process for azo dye containing wastewater treatment. HAR-BES showed faster start-up, 10\% higher azo dye decolorization efficiency, and 20\% higher COD removal efficiency than an aerobic reactor (AR) without electrode modules. Microbial community analysis showed functional diversity in electrode biofilm and sludge samples. Geobacter and Syntrophus, which would account for electrode respiration and reduction of azo dye, respectively, were dominant in electrode biofilms. Tracer experiments and modeling of residence time distribution indicated that the fluid pattern in HAR-BES was close to plug flow. Simulation of computational fluid dynamics showed faster water velocity near electrode modules and better sludge expansion in HAR-BES than AR. This study proved that HAR-BES improved anaerobic wastewater treatment comprehensively through the analysis of chemicals, microbial community, and modeling of fluid pattern.
\end{abstract}

\section{Introduction}

Bio-electrocatalyzed systems (BESs) can be a promising technology for organic wastewater treatment, due to less energy demand and sludge production, and resource recovery [1]. Most of BES studies have been conducted in laboratory scale from $1.5 \mu \mathrm{L}$ [2] to several liters [3]. Large-scale BESs $\left(\sim 1 \mathrm{~m}^{3}\right)$ were tested for power generation [4] or hydrogen generation [5]. However, the benefits brought by BESs were not significant due to substantial energy loss (e.g., voltage reversal in microbial fuel cells) or impurity of a target compound [6-8]. After

\footnotetext{
* Corresponding authors at: Key Laboratory of Environmental Biotechnology, Research Center for Eco-Environmental Sciences, Chinese Academy of Sciences, Beijing 100085, PR China (A.J. Wang).

E-mail addresses: xlzhuang@rcees.ac.cn (X.-L. Zhuang), ajwang@rcees.ac.cn (A.-J. Wang).
} 


\begin{tabular}{|c|c|c|}
\hline Nomenclature & $\begin{array}{l}\text { AYR } \\
\text { PPD }\end{array}$ & $\begin{array}{l}\text { Alizarin Yellow R } \\
\text { p-phenylenediamine }\end{array}$ \\
\hline bio-electrocatalyzed systems & 5-ASA & 5-aminosalicylic acid \\
\hline $\begin{array}{l}\text { HAR-BES hybrid anaerobic reactor built in with sleeve type elec- } \\
\text { trode modules }\end{array}$ & $\begin{array}{l}\text { VFAs } \\
\text { COD }\end{array}$ & $\begin{array}{l}\text { volatile fatty acids } \\
\text { chemical oxygen demand }\end{array}$ \\
\hline anaerobic reactor & ERE & electron recovery efficiency \\
\hline HAR-BES-S sludge zone of HAR-BES & RTD & retention time distribution \\
\hline HAR-BES-E bioelectrocatalyzed zone of HAR-BES & CFD & computational fluid dynamics \\
\hline Down-E down-electrode of bioelectrocatalyzed zone & DFM & disperse flow model \\
\hline Upper-E upper-electrode of bioelectrocatalyzed zone & mDFM & modified disperse flow model \\
\hline
\end{tabular}

(A)
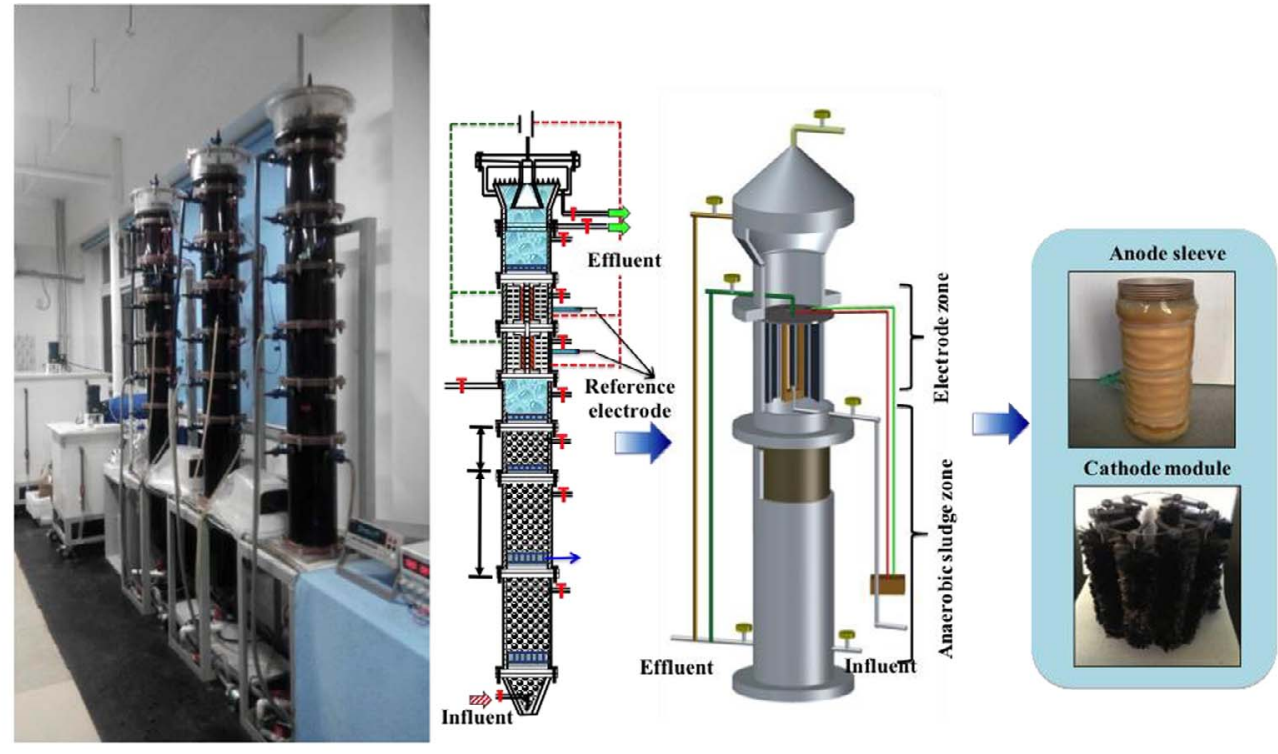

(B)

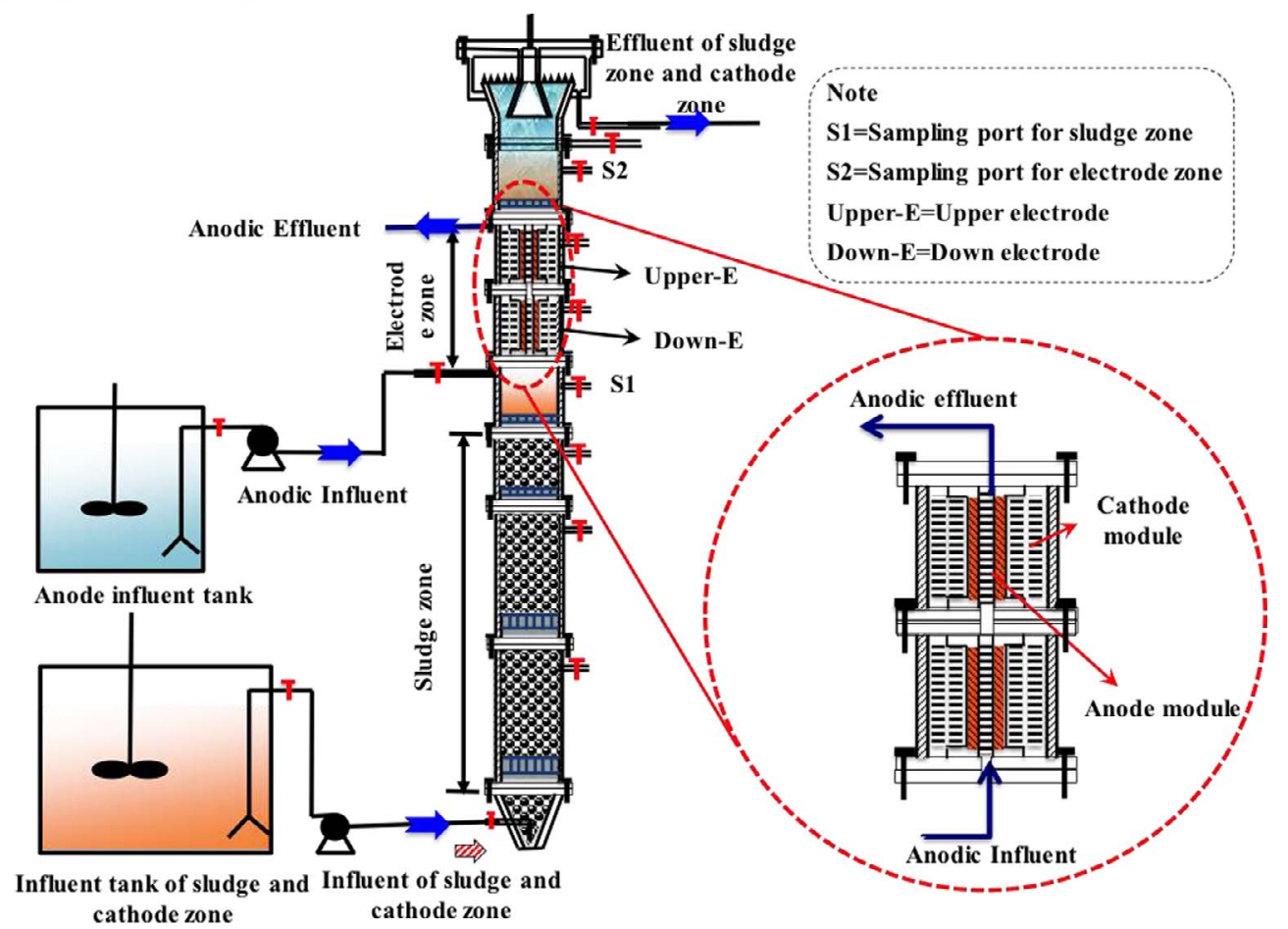

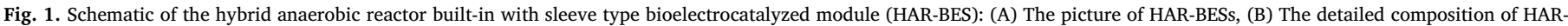
BESs. 
realizing the small merit of BESs, researchers attempted to utilize "anaerobic features of BESs" for wastewater treatment, improving sustainability (lack of aeration and reduction of sludge production). Especially, BES application for stabilization of refractory contaminants in industrial wastewater has gained attention due to serious toxic effects on human health, such as antibiotics $[9,10]$, nitrobenzene [11], halogenated compounds [12] and azo dyes [13,14].

Aerobic stabilization of refractory contaminants has been typically utilized for industrial wastewater treatment [15], while the contaminants can be reduced to innocuous forms of compounds by anaerobic processes [16]. Apparently, anaerobic treatment of refractory compounds is more economical than aerobic one, but anaerobic processes have shown relatively poor treatment efficiency for refractory wastewater as compared to aerobic processes [17], accounting for limited application of anaerobic technologies. Hence, improving stabilization of anaerobic treatment of refractory contaminants with BESs, another anaerobic technology, seems attractive, if BESs can further stabilize the contaminants. Integration of BESs with anaerobic processes can enhance the stabilization of refractory compounds, due to anode respiration and biotic/abiotic reduction of refractory substances on cathodes [18]. Anode-respiring bacteria in syntrophy with fermenters anaerobically oxidize biodegradable compounds with low energy input, reducing the demand for exogenous electron donor in anaerobic stabilization of refractory compounds [19]; thus, BESs can well complement existing anaerobic treatment processes. Placing individual processes in series (e.g., two-stage anaerobic digesters) is one mean of combining anaerobic processes with BESs. In comparison, installing BESs in existing anaerobic treatment processes (called, a hybrid anaerobic reactor (HAR-BES)) can be simpler, easier and more economical. For instance, HAR-BES will be very efficient for retrofitting existing anaerobic processes to improve treatment efficiency of refractory substances without significant investment. Literature has reported that coupling BES with an up-flow anaerobic sludge blanket enhanced degradation of $p$-nitrophenol (PNP), 2,4-dinitrochlorobenzene and azo dye with much less dosage of organic co-substrate [14,20,21]. Anaerobic baffled reactor and hydrolytic acidification bioreactor coupled with BESs improved azo dyes removal rate by $3-5$ times faster than a traditional anaerobic digester [22,23]. However, the contribution of BESs to stabilization of refractory contaminants and important parameters related to BESs (i.e., microbial community and hydrodynamics) in HAR-BES are unclear in literatures, which challenges the wide adoption of HAR-BES.

Another challenge in HAR-BES is the limitation of stabilizing refractory contaminants at high loading conditions, due to membrane-less BES configurations used elsewhere [20,22,24,25]. The anodic reactions would be seriously limited at high loading rate of refractory compounds (e.g. nitro aromatics, amino aromatics, halogenate, azo dye, etc.) in which a toxicity level of the compounds is high enough to inhibit metabolism of anodic bacteria [26]. Then, the contribution of BESs to stabilization of refractory compounds can be negligible at high loading. New BES designs, that can be readily scalable, applicable and complementary to conventional anaerobic treatment processes, should be developed to address this high loading challenge. Finally, information on large-scale BES experiments for treatment of refractory compounds is very limited, although scale-up tests are essential for wide adoption of HAR-BES.

The goals of this work are fourfold. First, we developed an innovative sleeve type BES (compact and scalable design) and tested a large-scale HAR-BES ( $30 \mathrm{~L})$. Second, we carefully assessed the contribution of BES to removal of refractory compound (azo dye) by operating two HAR-BESs (duplicate) and an anaerobic bioreactor without BES (control). Third, we investigated microbial community structures to better understand BES function to azo dye removal in HAR-BES. Finally, we conducted retention time distribution test (RTD) and simulated hydrodynamics with computational fluid dynamics (CFD) to characterize the hydraulic changes caused by BES and improvement of azo dye stabilization related to the hydrodynamics in large HAR-BES.

\section{Material and methods}

\subsection{Configuration of HAR-BES}

Fig. 1 showed the schematic of an up-flow hybrid anaerobic reactor coupled with BES (HAR-BES) constructed with eight Plexiglas cylindrical tubes (diameter: $15 \mathrm{~cm}$ ). Two bottom cylinders were $36 \mathrm{~cm}$ height and the other six cylinders were $18 \mathrm{~cm}$ height, respectively. The total volume of the reactor was $30 \mathrm{~L}$. HAR-BESs consist of sludge zone (HARBES-S) at the bottom and bioelectrocatalzyed zone (HAR-BES-E) above anaerobic sludge; bioelectrocatalyzed zone was divided into downelectrode (Down-E) and upper-electrode (Upper-E) modules, respectively (Fig. 1B). An anode module was installed in the center of each electrode module surrounded by a cathode module. The anode module was composed of a carbon brush $(\phi 5 \mathrm{~cm} \times \mathrm{H} 10 \mathrm{~cm}$, PANEX $33160 \mathrm{~K}$, ZOLTEK) installed in a plexiglas cylinder $(\phi 6 \mathrm{~cm} \times \mathrm{H} 15 \mathrm{~cm})$. Dozens of holes $(\phi 5 \mathrm{~mm})$ were drilled evenly in the surface of the cylinder to facilitate ion transport through cation exchange membrane (CEM, Ultrex CMI-7000, Membranes International, Ringwood, NJ, USA) pasted to the anode cylinder. The inlet and outlet of anode chamber were set at the bottom and the top of the cylinder, respectively. The cathode module consisted of 10 carbon brushes $(\phi 5 \mathrm{~cm} \times \mathrm{H} 15 \mathrm{~cm}$ ), which were connected in series with titanium wire. Two pairs of electrode modules were parallelly connected to $0.7 \mathrm{~V}$ of power supply. A $10 \Omega$ resistor was inserted to the wires for data collecting using a multimeter (Keithley 2700, Keithley Co., Ltd., USA). Two Ag/AgCl reference electrodes $(+0.197 \mathrm{~V}$ vs Standard hydrogen electrode, Shanghai Precision Scientific Instruments Co., Ltd., China) were placed in each pair of electrode module to measure electrode potentials every $10 \mathrm{~min}$.

\subsection{Inoculation and operation}

Three bioreactors were each inoculated with $10 \mathrm{~L}$ anaerobic sludge (Xiaohongmen wastewater treatment plant Beijing, China). Two HARBESs were operated in parallel to ensure the repeatability of data. All data was averaged for two HAR-BESs. An up-flow anaerobic reactor (AR) without electrode modules was operated as control to evaluate the function of electrode modules in HAR-BESs. The three reactors operated for $230 \mathrm{~d}$ with glucose medium $(0.5 \mathrm{~g} / \mathrm{L})$. Alizarin yellow R (AYR) was used as a model compound to azo dyes in this study. Glucose medium was fed to the bioreactors (sludge zone and cathode zone) as AYR concentration was changed from 0.05 to $0.2 \mathrm{~g} / \mathrm{L}$. The glucose medium contained (per L): sodium bicarbonate, $3 \mathrm{~g}$; glucose, $1.0 \mathrm{~g}$; NaCl, $1.5 \mathrm{~g}$; $\mathrm{NH}_{4} \mathrm{Cl}, 0.64 \mathrm{~g}$; yeast extract, $0.1 \mathrm{~g} ; \mathrm{CaCl}_{2}, 0.016 \mathrm{~g} ; \mathrm{FeCl}_{3}, 0.005 \mathrm{~g}$; $\mathrm{K}_{2} \mathrm{HPO}_{4}, 0.067 \mathrm{~g}$; trace element solution, $0.5 \mathrm{~mL}$ and vita- min solution, $0.5 \mathrm{~mL}$. The influent $\mathrm{pH}$ was $7.0 \pm 0.2$ and the effluent $\mathrm{pH}$ was close to neutral $\mathrm{pH}$, ranging from 7.0 to 6.8 . To maintain the stability of anode, the anode modules for HAR-BESs were fed with acetate + glucose $(1.0 \mathrm{~g} / \mathrm{L})$ medium separately (Fig. 1B). Our previous studies [13] have commonly shown moderate function of biofilm anodes, mainly due to substantial growth of microorganisms that cannot or poorly conduct extracellular electron transfer. Hence, we separately fed the anodic medium to the anode modules for enriching anode-respiring bacteria. The composition of (acetate + glucose) medium for the anode modules was potassium phosphate, $50 \mathrm{mM}$; sodium acetate, $0.5 \mathrm{~g} / \mathrm{L}$; glucose, $0.5 \mathrm{~g} / \mathrm{L}$, trace element solution, $1.0 \mathrm{~mL} / \mathrm{L}$ and vitamin solution, $1.0 \mathrm{~mL} /$ L. The (acetate + glucose) medium was continuously fed into the anode cylinders with a peristaltic pump (BT100-1 L, Longer Pump Co., Ltd., China) to keep a constant HRT of $12 \mathrm{~h}$.

The three bioreactors were run in batch mode for over $30 \mathrm{~d}$ (HRT $1 \mathrm{~d}$, based on the volume of the sludge and cathode zones (28.2 L)). The microorganisms for the anaerobic sludge zone and cathode module zone were acclimated with glucose medium containing AYR concentration of $50 \mathrm{mg} / \mathrm{L}$. Then, the influent AYR concentration was 
increased up to $80 \mathrm{mg} / \mathrm{L}$ when steady AYR removal efficiency was obtained over $70 \%$. After that, we operated the three bioreactors in continuous mode and varied operating conditions (HRT 12-4 h and AYR concentration 100-150 mg/L). Table 1 summarized the operating conditions from stage I to stage VI. We collected at least 10 data for individual stage. The reactors were operated at room temperature $\left(25 \pm 2{ }^{\circ} \mathrm{C}\right)$.

\subsection{Chemical analysis}

We sampled the effluent samples from the upper sampling ports in anaerobic sludge zone (HAR-BES-S) and electrode module zone (HARBES-E) of HAR-BESs (Fig. 1B). The samples were immediately filtered through a $0.22 \mu \mathrm{m}$ filter (Xingya Material Co., Shanghai, China) and diluted four times to quantify AYR, intermediates of AYR including $p$ phenylenediamine (PPD) and 5-aminosalicylic acid (5-ASA), and volatile fatty acids (VFA). AYR was measured using a UV-Vis spectrophotometer (Shimadzu UV2550, Japan) at wavelength of $374 \mathrm{~nm}$. PPD and 5-ASA concentrations were measured with a high performance liquid chromatography (HPLC, DGU 20A3 R, Shimadzu, Japan) equipped with a C18 column $(5 \mu \mathrm{m} ; 150 \times 4.6 \mathrm{~mm}$, Waters Co., Milford, MA, USA), according to literature [13,22]. Briefly describing, the mobile phase was methanol solution and $0.03 \%$ acetic acid solution with $1: 9$ ratio (vol/vol) at a flow rate of $1 \mathrm{~mL} \min 1$. The detection was performed at $288 \mathrm{~nm}$. VFAs were quantified with a HPLC equipped with an Animex column $(300 \mathrm{~mm} \times 7.8 \mathrm{~mm}$, Aminex HPX-87H Ion Exclusion Column, USA) and photo-diode array (PDA) detector at wavelength of $210 \mathrm{~nm}$. The mobile phase was $0.5 \% \mathrm{H}_{2} \mathrm{SO}_{4}$ (volume ratio) at a flow rate of $0.6 \mathrm{~mL} / \mathrm{min}$ and the injection volume was $50 \mu \mathrm{L}$. The chemical oxygen demand (COD) was measured with colorimetric COD test kits (100-1000 mg COD/L, Lian-hua Tech. Co., Ltd., China), according to manufacturer's instructions.

\subsection{Microbial community analysis}

After DNA extraction from samples using EZNA Soil DNA Kit (Omega Bio-Tek Inc., USA), we conducted 16S rRNA gene Illumina MiSeq sequencing. Amplicon libraries were constructed by Illumina Miseq 2000 using bacterial universal primers 341F and 805R for the V3-V4 region, and 349F and 806R for archaea. Both forward and reverse primers were added with barcode. Procedures for DNA extraction, measurement of DNA purity and quantity refers to the literature [27]. PCR products purification and quantification, and DNA sequencing were conducted by Huada Biotech Co., Ltd, China.

\subsection{Tracer test}

Aqueous $\mathrm{Li}_{2} \mathrm{SO}_{4}$ solution $(100 \mathrm{mg} / \mathrm{mL})$ was used as the tracer and the pulse input method was adopted for this study. $\mathrm{Li}_{2} \mathrm{SO}_{4}$ solution (2 $\mathrm{mL}$ ) was injected into HAR-BESs and AR in $0.5 \mathrm{~s}$, producing an average $\mathrm{Li}^{+}$concentration of $7 \mathrm{mg} / \mathrm{L}$ in the entire reactor. Samples were then collected from an effluent line with four HRT cycles for individual stages (HRT 12 to $4 \mathrm{~h}$ ). $\mathrm{Li}^{+}$concentration was qualified using inductively coupled plasma-optical emission spectroscopy (ICP-OES, OPTIMA 8300, PerkinElmer Co., USA) and its recoveries were more than $80 \%$ in all experiments.

\subsection{Residence time distribution (RTD) modeling}

Disperse flow model (DFM) and its modified model (mDFM) were selected to analyze the fluid dynamics in HAR-BES and AR.

The normalized time $\theta$ is calculated as follow:

$\theta=\frac{t}{\bar{t}}$

where $\bar{t}$ is the mean residence time:

$$
\begin{aligned}
& \bar{t}=\frac{\int_{0}^{\infty} c(t) d t}{\int_{0}^{\infty} c d t} \approx \frac{\sum \overline{c t} \Delta t}{\sum \bar{c} \Delta t} \\
& \overline{c t}=\frac{C_{i-1} t_{i-1}+C_{i} t_{i}}{2} \\
& \bar{c}=\frac{C_{i-1}+C_{i}}{2}
\end{aligned}
$$

where $c(t)$ is the tracer concentration at the outlet of the reactors. For the experimental data, the exit age distribution function $E(\theta)$ is expressed as follow:

$E(\theta)=\frac{C}{C_{N}}$

where $C_{\mathrm{N}}$ is the normalized concentration:

$C_{N}=\int_{0}^{\infty} c d \theta=\frac{\int_{0}^{\infty} C d t}{\bar{t}} \approx \frac{\sum \bar{C} \Delta t}{\bar{t}}$

The dimensionless variance $\sigma_{\theta}^{2}$ is as follow:

$\sigma_{\theta}^{2}=\int_{0}^{\infty} E(\theta)(\theta-1)^{2} d \theta=\frac{\sigma_{t}^{2}}{\bar{t}^{2}}$

where $\sigma_{t}^{2}$ is the variance with respect to $t$, it is calculated as follow:

$\sigma_{t}^{2}=\frac{\sum \overline{(t-\bar{t})^{2} C} \Delta t}{\bar{c} \Delta t}$

$\overline{(t-\bar{t})^{2} C}=\frac{\left(t_{i-1}-\bar{t}\right)^{2} C_{i-1}+\left(t_{i}-\bar{t}\right)^{2} C_{i}}{2}$

For DFM model, the exit age distribution function $E(\theta)$ is expressed as follow:

$E(\theta)=\frac{1}{\sqrt{4 \pi \theta(1 / P e)}} e^{-P e(1-\theta)^{2} 4 \theta}$

where $P e$ is the Peclet number [28]. The relationship between $P e$ and $\sigma_{t}^{2}$ is as follow:

$\sigma_{\theta}^{2}=\frac{2}{P e}-2\left(\frac{1}{P e}\right)^{2}\left(1-e^{-P e}\right)$

For the modified disperse flow model (mDFM), $E(\theta)$ is expressed as Eq. (12). The model building method was show in Supporting Information (SI) and reported elsewhere [29].

$E(\theta)=\sum \frac{f_{i}^{2}}{V_{i}} \frac{1}{\sqrt{4 \pi\left(f_{i} / V_{i}\right) \theta\left(1 / P e_{i}\right)}} e^{-P e_{i}\left(1-\left(f_{i} / V_{i}\right) \theta\right)^{2}} / 4\left(\frac{f_{i}}{V_{i}}\right) \theta$

wherer $f_{\mathrm{i}}$ is the volume flow rate fraction of $i$ th strand, $V_{\mathrm{i}}$ is the volume fraction of $i$ th strand, respectively.

The determination coefficient of $R^{2}$ between experiment and simulate data was calculated as follow:

Table 1

Operational condition of different stages.

\begin{tabular}{llllll}
\hline Stage & Time (d) & $\begin{array}{l}\text { Operational } \\
\text { Mode }\end{array}$ & HRT (h) & $\begin{array}{l}\text { AYR concentration } \\
(\mathrm{mg} / \mathrm{L})\end{array}$ & $\begin{array}{l}\text { AYR loading } \\
\text { rate }\left(\mathrm{g} / \mathrm{m}^{3} \cdot \mathrm{d}\right)\end{array}$ \\
\hline I & $0-30$ & Batch & $\begin{array}{l}24 \mathrm{~h} \\
(1 \mathrm{cycle})\end{array}$ & 80 & - \\
& & & 12 & 100 & 200 \\
II & $31-60$ & Continuous & 8 & 100 & 300 \\
III & $61-90$ & Continuous & 8 & 100 & 400 \\
IV & $91-120$ & Continuous & 6 & 150 & 600 \\
V & $121-150$ & Continuous & 6 & 150 & 800 \\
VI & $151-180$ & Continuous & 4 & &
\end{tabular}




$$
R^{2}=\frac{\left(\sum E(\theta)_{\exp } E(\theta)_{\operatorname{sim}}-\frac{\sum E(\theta)_{\exp } E(\theta)_{\operatorname{sim}}}{N}\right)^{2}}{\left(\sum E(\theta)_{\exp }^{2}-\frac{\left(\sum E(\theta)_{\exp }\right)^{2}}{N}\right)\left(\sum E(\theta)_{\operatorname{sim}}^{2}-\frac{\left(\sum E(\theta)_{\operatorname{sim}}\right)^{2}}{N}\right)}
$$

where $E(\theta)_{\exp }$ and $E(\theta)_{\text {sim }}$ were the exit age values of experiment and simulate, respectively. $N$ was the sampling number.

\subsection{Computational fluid dynamics (CFD) simulation}

A 2-D axisymmetric, steady CFD simulation was used to investigate the hydrodynamics of HAR-BESs and AR through commercially available CFD software (FLUENT). The Gambit pretreatment software was employed to build the model and to divide grids in simulated regions, which was treated as a 2-D plane because an axisymmetric space was adopted for the simulation in this study, as shown in Fig. S1. The detailed boundary conditions of this simulation are provided in the Supporting Information (SI).

Some hypotheses have been proposed to simplify the CFD simulation: (1) all carbon brushes were considered as perfect cylindrical zones and simplified as porous media, (2) anaerobic sludge were considered as tiny spheres (solid phase), (3) characteristics of liquid was the same with water, and (4) small structures in bioreactors, such as sampling ports, inlet tube, reference electrode, etc. were neglected.

\subsection{Calculations}

Decolorization efficiency of AYR $(D E, \%)$ and COD removal efficiency $\left(R E_{\mathrm{COD}}, \%\right)$ were calculated based on the difference between influent and effluent concentrations.

$D E=\left(C_{\mathrm{in}-\mathrm{AYR}}-C_{\mathrm{ef}-\mathrm{AYR}}\right) / C_{\mathrm{in}-\mathrm{AYR}} \times 100 \%$

$R E_{\mathrm{COD}}\left(C_{\mathrm{in}-\mathrm{COD}}-C_{\mathrm{ef}-\mathrm{COD}}\right) / C \mathrm{in}-\mathrm{COD} \times 100 \%$

where $C_{\text {in-AYR }}$ and $C_{\text {ef-AYR }}$ are the influent and effluent AYR concentrations, respectively, $\mathrm{mg} / \mathrm{L} ; C_{\text {in-COD }}$ and $C_{\text {ef-CoD }}$ were the influent and effluent COD concentration, respectively, $\mathrm{mg} / \mathrm{L}$.

Electron recovery efficiency (ERE\%) in HAR-BESs was calculated with equation (16):

$E R E=\frac{I \times 1000}{Q_{A} \times\left(C_{i n-E-A Y R}-C_{e f-E-A Y R}\right) \times 10 / 24 / 3600 \times F}$

where $I$ was the current, $\mathrm{mA} ; C_{\text {in-E-AYR }}$ and $C_{\text {ef-E-AYR }}$ were the influent and effluent AYR concentrations through the electrode zone. 10 is the molar number of electrons produced by complete reduction of $1 \mathrm{~mol}$ of AYR including of azo bond cleavage and amino reduction to nitro. $F$ is Faraday's constant $\left(96,485 \mathrm{C} / \mathrm{mol} \mathrm{e}^{-}\right) . E R E=1$ when all coulombs are used for AYR reduction on the cathode.

The AYR removal rate at the cathode calculated with ERE $\left(R R_{\mathrm{AYR}}\right.$ ERE, $\mathrm{g} / \mathrm{m}^{3} \cdot \mathrm{d}$ ) indicated the AYR amount removed by accepting electrons from the cathode.

$R R_{A Y R-E R E}=\left(C_{i n-A Y R} \times Q_{a} / V\right) \times D E_{E} \times E R E$

where $Q_{\mathrm{A}}$ is the influent flow rate, $\mathrm{m}^{3} / \mathrm{d}, V$ is the working reactor volume $\left(\mathrm{m}^{3}\right), D E_{\mathrm{E}}(\%)$ is the decolorization efficiency at the electrode zone.

\section{Results and discussion}

\subsection{Decolorization and COD removal}

During fed-batch mode (Stage I), azo dye and COD removal rates were both faster in HAR-BESs than those in AR. The decolorization efficiency of HAR-BESs reached at $73.7 \pm 4.2 \%$ within $6 \mathrm{~h}$, which was approximately $18 \%$ higher than that of AR (Fig. 2A). It quickly increased to $93.6 \pm 1.6 \%$ at $10 \mathrm{~h}$ and was as high as $94.9 \%$ during following $14 \mathrm{~h}$. In comparison, the decolorization efficiency in AR slowly increased to $75 \pm 1.9 \%$ at $10 \mathrm{~h}, 86.8 \pm 3.5 \%$ at $14 \mathrm{~h}$ and reached $93.3 \pm 1.5 \%$ at $24 \mathrm{~h}$. The average COD removal efficiency in HARBESs was $38.07 \pm 5.3 \%$, which was consistently better than that in AR (26.54 \pm 4.8\%) (Fig. 2B).

At stage II (HRT $12 \mathrm{~h}$, AYR $100 \mathrm{mg} / \mathrm{L}$ and AYR loading rate $200 \mathrm{~g} /$ $\mathrm{m}^{3} \cdot \mathrm{d}$ ), the overall decolorization efficiency was $96.5 \pm 1.5 \%$ in HARBESs ( $88.8 \pm 1.4 \%$ in the anaerobic sludge zone (HAR-BES-S) and $7.7 \pm 1.6 \%$ in the electrode zone (HAR-BES-E)), as shown in Fig. 2C. Decolorization efficiency was also high at $92.1 \pm 1.1 \%$ in AR. These results support that the decolorization of AYR mainly occurred in sludge zones for HRT $12 \mathrm{~h}$ (AYR loading $200 \mathrm{~g} / \mathrm{m}^{3} \cdot \mathrm{d}$ ). High decolorization efficiency (93.8 \pm 6.7-97.2 \pm 4.8\%) was consistently observed at HAR-BESs, although AYR loading rate was increased from 200 to $800 \mathrm{~g} \mathrm{AYR} / \mathrm{m}^{3} \cdot \mathrm{d}$ (HRT 12 to $4 \mathrm{~h}$ ). In comparison, AYR decolorization became poor in AR as AYR loading rate was increased (Fig. 2C). The decline of AYR decolorization at high AYR loading rate was also observed for the anaerobic sludge zone in HAR-BESs. The performance divergences of HAR-BES-S and AR were attributed to two reasons. First, in AR, azo dyes were removed through sludge bed and a large amount of suspension due to no electrode modules occupation. Bacteria in the suspension filling the reactor also contributed a part of azo dyes removal. In comparison, less suspension was involved in the sludge zone
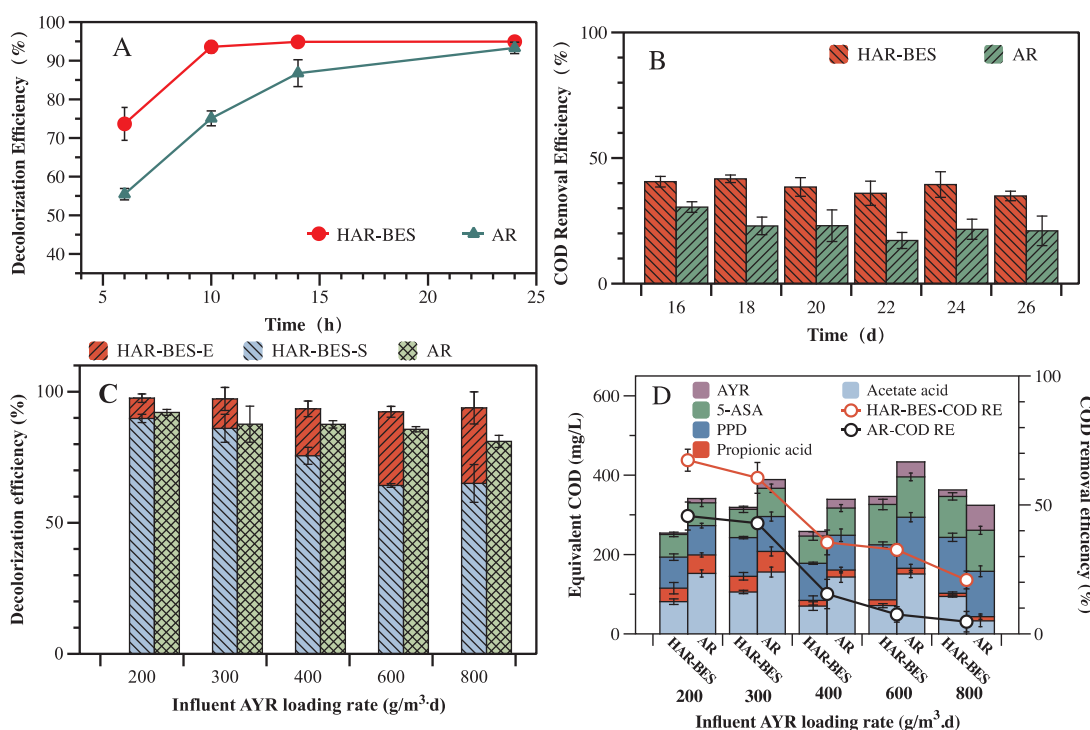

Fig. 2. Comparison of (A) decolorization and (B) COD removal efficiency of HAR-BES and AR at batch-fed period; (C) Decolorization efficiency variation of HAR-BES and AR at different AYR loading rates. HAR-BES-E: Electrode zone of HAR-BES, HAR-BES-S: Anaerobic sludge zone of HAR-BES; (D) COD removal efficiencies and the equivalent COD concentrations of AYR, 5-ASA, PPD, Propionic acid and acetate acid in the effluent of HAR-BES and AR at different AYR loading rates. 
of HAR-BES because the samples were just taken from the upper of sludge zone. Second, the flow velocity speeded up near the bottom of electrode modules, which probably led to a partial back mixing near the outlet of sludge zone. This would resulted in the measured decolorization efficiency was lower. However, the decolorization efficiency in the electrode zone increased from $7.7 \pm 1.6$ to $28.9 \pm 6.1 \%$ at high AYR loading rates, implying that AYR decolorization in the electrode modules became significant at short HRTs. The superficial liquid velocity from $0.22-0.66 \mathrm{~cm} / \mathrm{min}$ led to small Reynolds numbers ranging from 5.5 to 16.6. This calculation implies that the bioreactors were operated in laminar regime and diffusion would be significant for mass transport in the bioreactors. We further studied hydrodynamic conditions in the bioreactors using model simulations later.

The reductive products of AYR (PPD and 5-ASA) and main VFAs (acetate and propionate) were further compared (Fig. 2D). PPD and 5ASA are typically accumulated in the anaerobic reduction of AYR $[13,22]$, which were not different much between HAR-BESs and AR. The formation efficiencies of PPD and 5-ASA were steady higher than $90 \%$. However, COD removal efficiency in HAR-BESs was constantly higher than that in AR. The concentrations of acetic acid and propionic acid, main VFAs, were consistent to COD removal (Fig. 2D and Fig. S1) in HRT longer than $4 \mathrm{~h}$, implying that compounds unidentified with the HPLC might be accumulated in AR. The higher COD removal in HARBESs would be related to enhanced methanogenesis [30].

\subsection{Electrochemical contribution of electrode modules in HAR-BESs}

Anode and cathode potentials in upper and down electrodes were constant to AYR loading rates, suggesting that anodic (acetate oxidation) and cathodic reactions (AYR reduction) would be relatively steady during the experiments (Fig. 3A). The current and electron recovery efficiency were used to assess azo dye decolorization at the cathode via electrochemical reduction. As shown in Fig. 3B, the total current generated from the two electrode modules (upper and down) increased from $12.2 \pm 1.4$ to $19.55 \pm 2.1 \mathrm{~mA}$ as AYR loading rate increasing. In contrast, high electron recovery efficiency (approximately $\sim 81 \%$ ) at lower AYR loading significantly decreased to $8.2 \%$ at the highest AYR loading rate (Fig. 3C). Increased current and decreased electron recovery efficiency means that bioelectrochemical reaction was improved but a larger amount of azo dye was reduced by non electro-active bacteria (Fig. S2). This pattern is consistent to our previous work [31]. AYR removal via accepting cathodic electrons ( $\left.R R_{\text {AYR-ERE }}\right)$ was estimated at $12.48-18.95 \mathrm{~g} / \mathrm{m}^{3} \cdot \mathrm{d}$. This means that the AYR removal rate via pathway I (Fig. S2) did not decline but kept stable or slightly increased. It seemed that the cathode capacity for AYR removal via Pathway I would be close to saturation. One possible reason for this might be limited exposure of active sites of the cathode to AYR. In the hybrid system, we observed that thick biofilm formed and covered the cathode surface (Fig. S3), which may cause the inhomogeneous reaction at the cathode.

\subsection{Biodiversity and shifts in microbial community structure and composition}

The observed numbers of operational taxonomic units (OTUs) of bacterial sequences were 328, 447, 478 and 441 for the anode biofilm (HAR-BES-Anode), cathode biofilm (HAR-BES-Cathode), sludge in HAR-BESs (HAR-BES-Sludge) and sludge in AR (AR-Sludge), respectively. Only 179 OTUs shared by them indicates a significant difference of microbial communities in the four samples (Fig. 4A). The highest Chao 1 and Shannon indexes (504.96 and 3.68) were obtained in the HAR-BES-Sludge community, which were relatively higher than those in the AR-Sludge community, i.e., 479.23 and 3.54. The shared OTUs between the anode biofilm in HAR-BESs and the other three samples were relatively low. The Chao 1 and Shannon indexes for the anode biofilm were the lowest ( 361.75 and 3.32 ), supporting the unique feature of anode respiration. The similarities of microbial community structures in the four samples were further compared by hierarchically clustered heatmap analysis (Fig. 4B). Obvious differences were visualized between them at phylum level, especially for electrode biofilm and sludge communities. HAR-BES-Sludge and AR-Sludge were very close.

A total of 38 phyla were identified in the four samples. The dominant phyla included Bacteroidetes, Chloroflexi, Firmicutes, Proteobacteria, Synergistetes, Thermotogae and WWE1 (Fig. 4B). The relative abundances of Bacterioidetes were the highest in each sample, which were $30.18 \%$, $38.63 \%, 47.30 \%$ and $39.70 \%$, respectively, for HAR-BES-Anode, HARBES-Cathode, HAR-BES-Sludge, and AR-Sludge. The relative abundances of Proteobacteria and Chorobi in the biofilm anode (HAR-BESAnode) were remarkably higher than those in the other three samples; HAR-BES-Cathode enriched more Proteobacteria species than that of the other two sludge samples. In comparison, the relative abundance of WWEI in the anode biofilm presented much lower (0.097\%) than that in the other three samples. This suggested that Proteobacteria and Chorobi
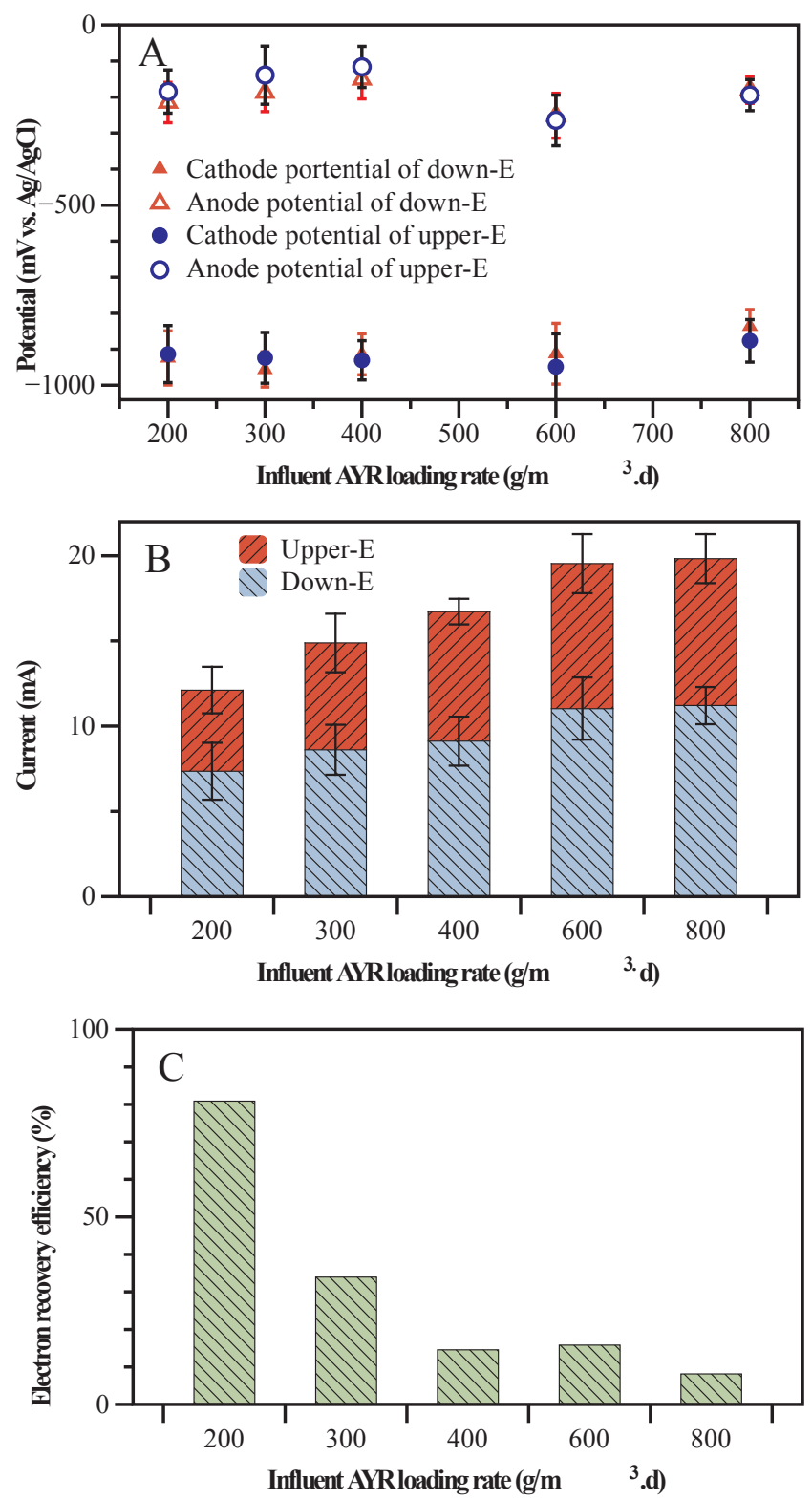

Fig. 3. (A) Cathode and anode potentials of upper and down electrode modules, (B) The current of the upper (Upper-E) and down (Down-E) electrode module in HAR-BES, (C) Electron recovery efficiency (ERE) of HAR-BES at different AYR loading rates. 


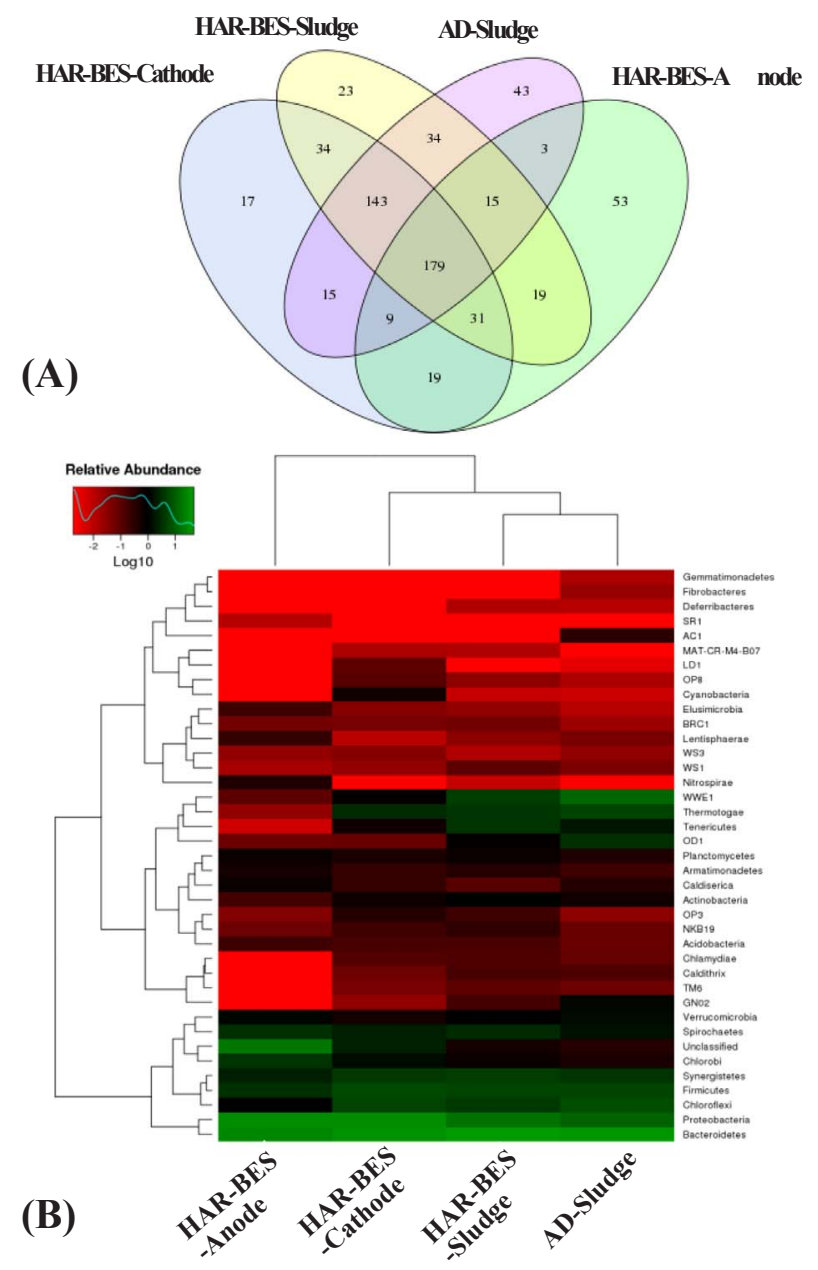

Fig. 4. (A) OTU Venn analysis and (B) hierarchical clustering from the four communities (HAR-BES-Anode, HAR-BES-Cathode, HAR-BES-Sludge and AR-Sludge) at phylum level.

phyla would be main players for anode respiration.

A total of 268 genera were classified among the four samples. Seventeen genera with relative abundance $>0.5 \%$ were shown in Table 2. Syntrophus and Geobacter were dominant in the electrode biofilms in HAR-BESs. The relative abundances of Syntrophus and Geobacter were $11.91 \%$ and $7.60 \%$ for HAR-BES-Anode, and $17.91 \%$ and $5.01 \%$ for HAR-BES-Cathode, respectively. Geobactor has been identified for anode respiration [32-34]. Syntrophus and Geobacter identified on the cathode biofilm indirectly indicate that bioelectrochemical reduction of AYR or protons to $\mathrm{H}_{2}$ might occur. Several works reported Syntrophus and Geobacter were related to the reduction of nitro- and azo-aromatics [35-37] or biocathode for $\mathrm{H}_{2}$ production [38].

Desulfobulbus and Kosmotoga were enriched in HAR-BES-Sludge and AR-Sludge, implying that they would mainly reduce azo dye in sludge phase. Desulfobulbus was fermentative bacteria, which have often been observed as a dominant fermenter in up-flow anaerobic sludge blanket. Kosmotoga, another fermenting bacteria, can ferment carbohydrates and accumulate VFAs [39]. Previous study [40] suggested that Kosmotoga would establish syntrophic interactions with Geobacter genus in the presence of fermentable substrate for anode respiration.

For Archaea, 27 OTUs and 17 genera were observed. There was no obvious difference between the Archaea communities of the four samples with 14 OTUs shared (Fig. S3). Methanogens including
Methocorpuseulum and Methanosaeta were dominant in sludge and biofilm samples, but more at electrode biofilms of HAR-BESs (Fig. S4). Larger population of methanogens in HAR-BESs supports that $\mathrm{H}_{2}$ would be produced at the cathode, stimulating growth of methanogens in HAR-BESs. In addition, methanogens' abundance in electrode biofilms accords to higher COD removal in HAR-BESs (Fig. 2D). More population of Methanosaeta sp., that typically utilizes acetate as substrate, in the anode biofilm is reasonable because of acetate medium fed to the anode modules. Less population of Methocorpuseulum sp. than that of Methanosaeta sp. on the cathode biofilm seems to indicate that acetate and propionate accumulated in cathode zones would be converted to methane, along with methane production from $\mathrm{H}_{2}$.

\subsection{Hydrodynamics}

3.4.1. Resistance time distribution (RTD) comparison between HAR-BESs and $A R$

The RTD curves for HAR-BESs and AR were similar to each other (Fig. 5). Only one peak was observed from each RTD curve at four different HRTs, indicating no serious short-circuiting stream or preferential flow occurring in HAR-BES and AR. Much longer tails were observed in RTD curves of AR, which means stagnant or dead zones created in AR. Thus, the release of tracer $\mathrm{Li}^{+}$was slow in these regions. The results of tracer tests also indicated that the actual HRTs in AR were shorter than theoretical HRTs. In comparison, the actual HRTs in HARBESs were close to or longer than the theoretical ones probably due to the introduction of electrode modules that could uniform the flow regime and prolong fluid path.

Dispersion model or dispersed flow model (DFM) is typically used to model RTD. DFM was established if longitudinal dispersion is the main cause for deviation from ideal flow in a conduit reactor (i.e. a tube, pipe, or channel). In this work, DFM model was firstly used to simulate the hydrodynamics of the non-ideal flow reactors to see how well the RTD curves could fit to this model. The RTD curves of HAR-BES and AR under four HRTs were shown in Fig. 5. For HAR-BES, the normalized time $\theta$ of the response peak in RTD curves was close to 1 , but they were much smaller than 1 for AR, indicating more dead zones in AR [41]. The tracer test results for AR did not fit DFM well at shorter HRTs; the determination coefficients $\left(\mathrm{R}^{2}\right)$ were $0.28,0.78$ and 0.79 at HRT of 4,6 , $8 \mathrm{~h}$ in order. However, the results matched DFM simulation better for HAR-BESs especially at HRTs of 8 and $6 \mathrm{~h}$ with $\mathrm{R}^{2}$ of 0.93 and 0.96 , respectively. These results imply that the hydrodynamics in HAR-BESs was much close to plug flow as we expected, due to the electrode modules distributing flow uniformly near the outlet. In order to get insight into the flow property and obtain a more appropriate model for

Table 2

Microbial communities at genus level.

\begin{tabular}{lllll}
\hline Relative abundance (\%) & $\begin{array}{l}\text { HAR-BES- } \\
\text { Anode }\end{array}$ & $\begin{array}{l}\text { HAR-BES- } \\
\text { Cathode }\end{array}$ & $\begin{array}{l}\text { HAR-BES- } \\
\text { Sludge }\end{array}$ & AR-Sludge \\
\hline Syntrophus & 11.91 & 17.91 & 4.38 & 1.31 \\
Desulfobulbus & 0.37 & 1.91 & 4.53 & 5.96 \\
Desulfovibrio & 3.25 & 0.96 & 0.18 & 0.05 \\
Geobacter & 7.60 & 5.01 & 1.59 & 0.69 \\
Kosmotoga & 0.029 & 2.93 & 3.91 & 5.68 \\
Desulfomicrobium & 0.01 & 0.35 & 0.27 & 0.65 \\
HA73 & 0.84 & 3.26 & 3.73 & 2.66 \\
Propionivibrio & 2.31 & 0.005 & 0.02 & 0.004 \\
SHD-231 & 0.11 & 0.95 & 0.72 & 1.11 \\
Syntrophomonas & 0.60 & 0.87 & 0.46 & 0.17 \\
Candidatus_Cloacamonas & 0 & 0.33 & 1.61 & 1.28 \\
E6 & 0.08 & 0.57 & 0.49 & 0.20 \\
Longilinea & 0.17 & 0.91 & 1.16 & 0.79 \\
T78 & 0.06 & 1.14 & 0.79 & 1.20 \\
Tissierella_Soehngenia & 0 & 0.41 & 0.65 & 1.27 \\
Treponema & 2.57 & 1.25 & 1.75 & 1.07 \\
vadinCA02 & 1.08 & 0.63 & 0.48 & 1.01 \\
\hline
\end{tabular}



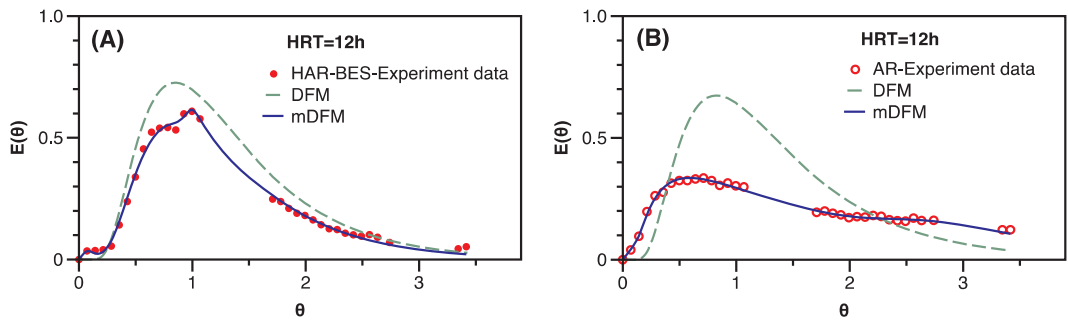

Fig. 5. RTD curve and simulation results with DFM and mDFM at various HRTs.
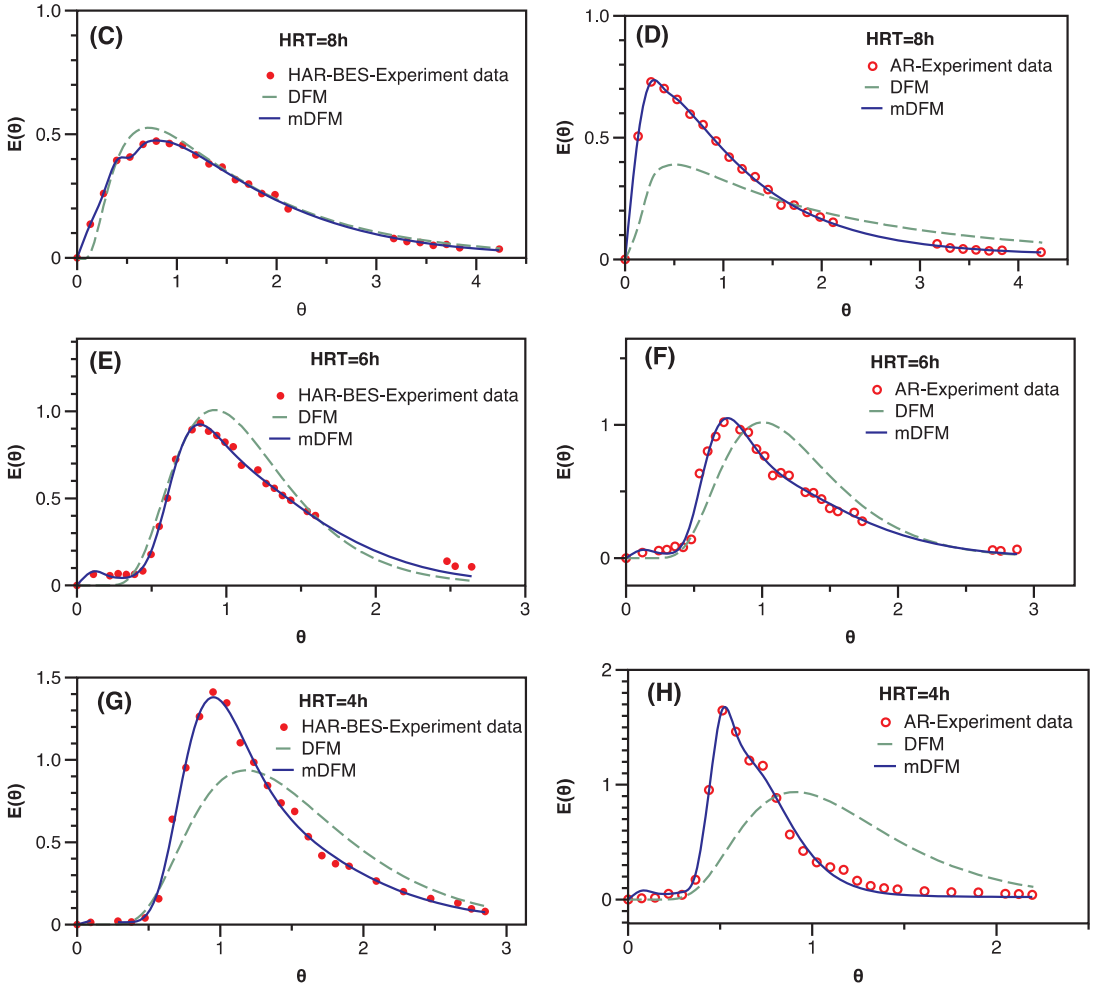

the hydrodynamic characteristics in HAR-BESs, a modified non-ideal flow model based on DFM (mDFM) was established. The model was divided into multi parallel stands as shown in Eq. (S1) and the estimated values of different parameters for MDFM were shown in Table S1. Compared to DMF, the mDFM with three parallel stands fitted the experimental RTD curves better (Fig. 5), showing that $R^{2}$ for HAR-BESs and AR were higher than 0.99 (Table 3).

The $P e$ number (the ratio between mass transports by advection to dispersion) is the single parameter in DFM and mDFM. Larger Pe number means mass transport more controlled by advection, but less axial dispersion occurs. As shown in Table 3, the Pe numbers for HARBESs was higher than those of AR, which also indicates a less degree of mixing by axial dispersion in HAR-BES.

\subsubsection{Flow pattern visualization through CFD simulation}

CFD simulations were used to further investigate the hydrodynamics in bioreactors. Exact dimensions of the actual HAR-BESs and AR described in the previous sections were used to construct a two-dimensional model (Fig. S5). From the results of CFD simulations, water flow velocity profiles and sludge volume fraction distribution plots were generated for different water and sludge depths at different HRTs. Decreasing HRT resulted in higher velocities both in HAR-BES and AR. In HAR-BES, electrodes occupied in the middle part of the up-flow region and shirked the cross-sectional area compared to sludge zone. Thus, the water flow velocity in the electrode zone was relatively higher than that sludge zone. The water flow velocity increased between the electrode module and reactor boundary in HAR-BESs due to narrow flow channels, which resulted in nearly 2-3 times higher velocities at the upper field of HAR-BESs than that of AR (Fig. 6A-B). This increase of water flow near the electrode modules might contribute to improving mass transport to electrode surface and potentially decolorization in electrode modules. In addition, sludge volume fraction was another significant reactor hydrodynamic characteristic. Our CFD simulations showed larger sludge volume fraction in HAR-BESs even in longer HRTs, which could facilitate biodegradation in sludge zone with less sludge dead zone (Fig. 6 C-D).

\section{Conclusions}

HAR-BESs seem to be a feasible alternative anaerobic process for the treatment of refractory wastewater with high pollutant loading rate (e.g. azo dye). The presence of electrode modules accelerated azo dye

Table 3

Hydraulic variables comparison between HAR-BES and AR.

\begin{tabular}{llllll}
\hline Model & HRT (h) & R2 & & \multicolumn{2}{l}{ Pe (Peclet number) } \\
\hline \multirow{4}{*}{ DFM } & & HAR-BES & AR & HAR-BES & AR \\
& 4 & 0.76 & 0.28 & 11.94 & 6.43 \\
& 6 & 0.93 & 0.78 & 8.09 & 8.37 \\
& 8 & 0.96 & 0.79 & 2.94 & 1.33 \\
mDFM & 12 & 0.77 & 0.94 & 2.20 & 1.27 \\
& 4 & 0.995 & 0.99 & $\mathbf{2 7 . 9 6}$ & $\mathbf{1 1 . 9 8}$ \\
& 6 & 0.995 & 0.983 & $\mathbf{1 3 . 3 4}$ & $\mathbf{1 5 . 9 1}$ \\
& 8 & 0.998 & 0.999 & $\mathbf{9 . 2 2}$ & $\mathbf{3 . 0 7}$ \\
& 12 & 0.994 & 0.992 & $\mathbf{8 . 7 3}$ & $\mathbf{3 . 7 1}$ \\
\hline
\end{tabular}




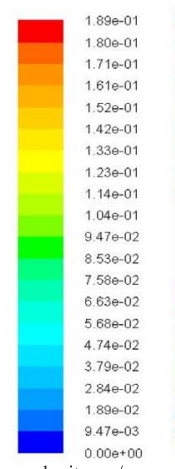

(A)

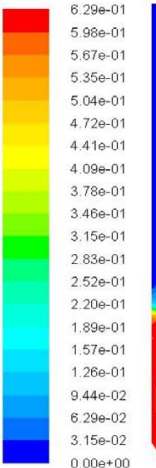

sludge-volume

(C)

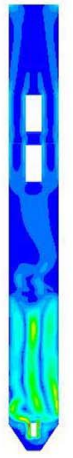

$12 \mathrm{~h}$

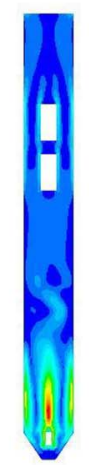

8h

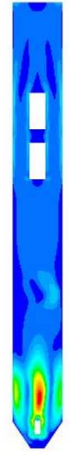

$6 \mathrm{~h}$

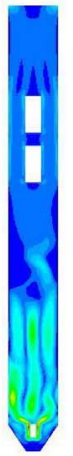

$4 h$

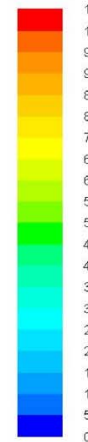

velocity: $\mathrm{m} / \mathrm{s}$

(B)

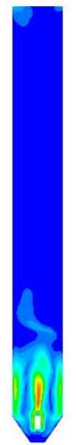

$12 \mathrm{~h}$

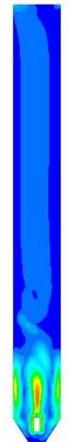

$8 h$
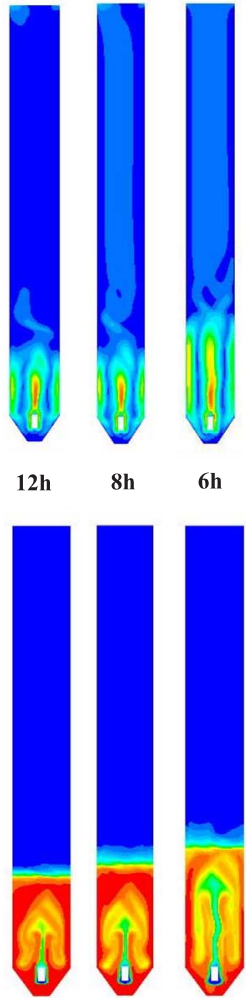

$6 \mathrm{~h}$

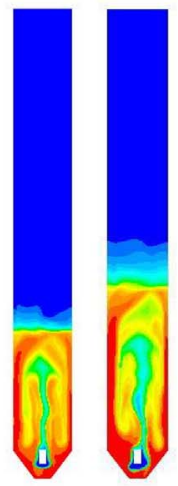

(D) sludge-volume

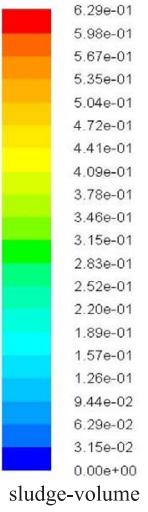

$12 \mathrm{~h}$

$\mathbf{8 h}$

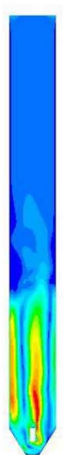

4h

4h
Fig. 6. Water velocity distributions of (A) HAR-BES and (B) AR; sludge volume fraction distributions of (C) HAR-BES and (D) AR at different HRTs. decolorization and COD removal, especially at shorter HRT (e.g. 4 h). The vertical set of electrode module and sludge bed and the sleevedesign of cathode and anode modules not only increased the microbial diversity, but also separated microorganisms with special functions. The fluid pattern of HAR-BESs was much close to plug flow that could be well simulated by DFM model. The water flow and sludge velocities were both promoted in HAR-BESs comparing with that in AR, which supplied efficient contact between microbes and wastewater. This study provides a comprehensive understanding of the hybrid anaerobic system. And it is meaningful for optimizing this hybrid system further to boost the development of anaerobic process.

\section{Acknowledgement}

This work was financially supported by the National Natural Science Foundation of China (Nos. 51508551 and 21577162) and the China Postdoctoral Science Foundation (Nos. 2016T90142 and 2015M580140).

\section{Appendix A. Supplementary data}

Supplementary data associated with this article can be found, in the online version, at http://dx.doi.org/10.1016/j.cej.2017.07.167.

\section{References}

[1] B.E. Logan, K. Rabaey, Conversion of wastes into bioelectricity and chemicals by using microbial electrochemical technologies (vol 337, pg 686, 2012), Science 339 (2013) 906-906.

[2] F. Qian, M. Baum, Q. Gu, D.E. Morse, A $1.5 \mu \mathrm{L}$ microbial fuel cell for on-chip bioelectricity generation, Lab Chip 9 (2009) 3076-3081.

[3] D.Q. Jiang, B.K. Li, Granular activated carbon single-chamber microbial fuel cells (GAC-SCMFCs): a design suitable for large-scale wastewater treatment processes, Biochem. Eng. J. 47 (2009) 31-37.

[4] L.M. Tender, S.A. Gray, E. Groveman, D.A. Lowy, P. Kauffman, J. Melhado, R.C. Tyce, D. Flynn, R. Petrecca, J. Dobarro, The first demonstration of a microbial fuel cell as a viable power supply: Powering a meteorological buoy, J. Power Sources 179 (2008) 571-575.

[5] B.E. Logan, Scaling up microbial fuel cells and other bioelectrochemical systems, Appl. Microbiol. Biot. 85 (2010) 1665-1671.

[6] J. An, B. Kim, I.S. Chang, H.S. Lee, Shift of voltage reversal in stacked microbial fuel cells, J. Power Sources 278 (2015) 534-539.

[7] H.S. Lee, B.E. Rittmann, Significance of biological hydrogen oxidation in a continuous single-chamber microbial electrolysis cell, Environ. Sci. Technol. 44 (2010) 948-954.

[8] S.A. Cheng, D.F. Xing, D.F. Call, B.E. Logan, Direct biological conversion of electrical current into methane by electromethanogenesis, Environ. Sci. Technol. 43 (2009) 3953-3958.

[9] B. Liang, D.Y. Kong, J.C. Ma, C.Q. Wen, T. Yuan, D.J. Lee, J.Z. Zhou, A.J. Wang, Low temperature acclimation with electrical stimulation enhance the biocathode functioning stability for antibiotics detoxification, Water Res. 100 (2016) 157-168.

[10] B. Liang, H.Y. Cheng, D.Y. Kong, S.H. Gao, F. Sun, D. Cui, F.Y. Kong, A.J. Zhou, W.Z. Liu, N.Q. Ren, W.M. Wu, A.J. Wang, D.J. Lee, Accelerated reduction of chlorinated nitroaromatic antibiotic chloramphenicol by biocathode, Environ. Sci. Technol. 47 (2013) 5353-5361.

[11] B. Liang, H.Y. Cheng, J.D. Van Nostrand, J.C. Ma, H. Yu, D.Y. Kong, W.Z. Liu, N.Q. Ren, L.Y. Wu, A.J. Wang, D.J. Lee, J.Z. Zhou, Microbial community structure and function of Nitrobenzene reduction biocathode in response to carbon source switchover, Water Res. 54 (2014) 137-148.

[12] S.T. Lohner, D. Becker, K.M. Mangold, A. Tiehm, Sequential reductive and oxidative biodegradation of chloroethenes stimulated in a coupled bioelectro-process, Environ. Sci. Technol. 45 (2011) 6491-6497.

[13] D. Cui, Y.Q. Guo, H.Y. Cheng, B. Liang, F.Y. Kong, H.S. Lee, A.J. Wang, Azo dye removal in a membrane-free up-flow biocatalyzed electrolysis reactor coupled with an aerobic bio-contact oxidation reactor, J. Hazard. Mater. 239 (2012) 257-264.

[14] M.H. Cui, D. Cui, L. Gao, A.J. Wang, H.Y. Cheng, Azo dye decolorization in an upflow bioelectrochemical reactor with domestic wastewater as a cost-effective yet highly efficient electron donor source, Water Res. 105 (2016) 520-526.

[15] Q. Zhao, Y. Liu, State of the art of biological processes for coal gasification was tewater treatment (vol 34, pg 1064, 2016), Biotechnol. Adv. 34 (2016) (2016) 1442-1442.

[16] W.P. Barber, D.C. Stuckey, The use of the anaerobic baffled reactor (ABR) for wastewater treatment: A review, Water Res. 33 (1999) 1559-1578.

[17] R. Rajagopal, D.I. Masse, G. Singh, A critical review on inhibition of anaerobic digestion process by excess ammonia, Bioresour. Technol. 143 (2013) 632-641.

[18] L.P. Huang, S.A. Cheng, G.H. Chen, Bioelectrochemical systems for efficient recalcitrant wastes treatment, J. Chem. Technol. Biot. 86 (2011) 481-491.

[19] Y. Mu, R.A. Rozendal, K. Rabaey, J. Keller, Nitrobenzene removal in bioelectrochemical systems, Environ. Sci. Technol. 43 (2009) 8690-8695.

[20] J.Y. Shen, X.P. Xu, X.B. Jiang, C.X. Hua, L.B. Zhang, X.Y. Sun, J.S. Li, Y. Mu, L.J. Wang, Coupling of a bioelectrochemical system for p-nitrophenol removal in an 
upflow anaerobic sludge blanket reactor, Water Res. 67 (2014) 11-18.

[21] X.B. Jiang, J.Y. Shen, Y. Han, S. Lou, W.Q. Han, X.Y. Sun, J.S. Li, Y. Mu, L.J. Wang Efficient nitro reduction and dechlorination of 2,4-dinitrochlorobenzene through the integration of bioelectrochemical system into upflow anaerobic sludge blanket: a comprehensive study, Water Res. 88 (2016) 257-265.

[22] D. Cui, Y.Q. Guo, H.S. Lee, W.M. Wu, B. Liang, A.J. Wang, H.Y. Cheng, Enhanced decolorization of azo dye in a small pilot-scale anaerobic baffled reactor coupled with biocatalyzed electrolysis system (ABR-BES): a design suitable for scaling-up, Bioresour. Technol. 163 (2014) 254-261.

[23] H.C. Wang, H.Y. Cheng, S.S. Wang, D. Cui, J.L. Han, Y.P. Hu, S.G. Su, A.J. Wang, Efficient treatment of azo dye containing wastewater in a hybrid acidogenic bioreactor stimulated by biocatalyzed electrolysis, J. Environ. Sci.-Chin. 39 (2016) 198-207.

[24] A.J. Wang, D. Cui, H.Y. Cheng, Y.Q. Guo, F.Y. Kong, N.Q. Ren, W.M. Wu, A membrane-free, continuously feeding, single chamber up-flow biocatalyzed electrolysis reactor for nitrobenzene reduction, J. Hazard. Mater. 199 (2012) 401-409.

[25] Y. Wang, C.G. Niu, G.M. Zeng, W.J. Hu, D.W. Huang, M. Ruan, Microbial fuel cell using ferrous ion activated persulfate as a cathodic reactant, Int. J. Hydrogen Energy 36 (2011) 15344-15351.

[26] L. Wang, Y.L. Liu, J. Ma, F. Zhao, Rapid degradation of sulphamethoxazole and the further transformation of 3-amino-5-methylisoxazole in a microbial fuel cell, Water Res. 88 (2016) 322-328.

[27] Y.Y. Qu, Q. Ma, J. Deng, W.L. Shen, X.W. Zhang, Z.L. He, J.D. Van Nostrand, J.T. Zhou, J.Z. Zhou, Responses of microbial communities to single-walled carbon nanotubes in phenol wastewater treatment systems, Environ. Sci. Technol. 49 (2015) 4627-4635.

[28] C.W. Hirt, B.D. Nichols, Volume of fluid (Vof) method for the dynamics of free boundaries, J. Comput. Phys. 39 (1981) 201-225.

[29] H.C. Wang, H.Y. Cheng, D. Cui, B. Zhang, S.S. Wang, J.L. Han, S.G. Su, R. Chen, A.J. Wang, Corrugated stainless-steel mesh as a simple engineerable electrode module in bio-electrochemical system: Hydrodynamics and the effects on decolorization performance, J. Hazard. Mater. 338 (2017) 287-295.

[30] X.B. Jiang, J.Y. Shen, S. Lou, Y. Mu, N. Wang, W.Q. Han, X.Y. Sun, J.S. Li, L.J. Wang, Comprehensive comparison of bacterial communities in a membrane- free bioelectrochemical system for removing different mononitrophenols from wastewater, Bioresour. Technol. 216 (2016) 645-652.

[31] M.H. Cui, D. Cui, H.S. Lee, B. Liang, A.J. Wang, H.Y. Cheng, Effect of electrode position on azo dye removal in an up-flow hybrid anaerobic digestion reactor with built-in bioelectrochemical system, Sci. Rep. 6 (2016).

[32] B.E. Logan, Exoelectrogenic bacteria that power microbial fuel cells, Nat. Rev. Microbiol. 7 (2009) 375-381.

[33] S.M. Caffrey, H.S. Park, J. Been, P. Gordon, C.W. Sensen, G. Voordouw, Gene expression by the sulfate-reducing bacterium Desulfovibrio vulgaris Hildenborough grown on an iron electrode under cathodic protection conditions, Appl. Environ. Microb. 74 (2008) 2404-2413.

[34] K.B. Gregory, D.R. Bond, D.R. Lovley, Graphite electrodes as electron donors for anaerobic respiration, Environ. Microbiol. 6 (2004) 596-604.

[35] G.F. Liu, J.T. Zhou, C.C. Chen, J. Wang, R.F. Jin, H. Lv, Decolorization of azo dyes by Geobacter metallireducens, Appl. Microbiol. Biot. 97 (2013) 7935-7942.

[36] H. Yun, B. Liang, D.Y. Kong, H.Y. Cheng, Z.L. Li, Y.B. Gu, H.Q. Yin, A.J. Wang, Polarity inversion of bioanode for biocathodic reduction of aromatic pollutants, J. Hazard. Mater. 331 (2017) 280-288.

[37] J.W. Kung, J. Seifert, M. von Bergen, M. Boll, Cyclohexanecarboxyl-Coenzyme A (CoA) and cyclohex-1-ene-1-carboxyl-coa dehydrogenases, two enzymes involved in the fermentation of benzoate and crotonate in syntrophus aciditrophicus, J. Bacteriol. 195 (2013) 3193-3200.

[38] W.W. Cai, W.Z. Liu, C.X. Yang, L. Wang, B. Liang, S. Thangavel, Z.C. Guo, A.J. Wang, Biocathodic methanogenic community in an integrated anaerobic digestion and microbial electrolysis system for enhancement of methane production from waste sludge, ACS Sustain. Chem. Eng. 4 (2016) 4913-4921.

[39] J.L. DiPippo C.L. Nesbo H. Dahle W.F. Doolittle N.K. Birkland K.M. Noll Kosmotoga olearia gen. nov., sp nov., a thermophilic, anaerobic heterotroph isolated from an oil production fluid Int. J. Syst. Evol. Micrbiol. 59200929913000.

[40] Y.H. Gao, J.Y. An, H.D. Ryu, H.S. Lee, Microbial fuel cells as discontinuous portable power sources: syntropic interactions with anode- respiring bacteria, Chemsuschem 7 (2014) 1026-1029.

[41] Y.Z. Wang, Y.K. Wang, C.S. He, H.Y. Yang, G.P. Sheng, J.Y. Shen, Y. Mu, H.Q. Yu, Hydrodynamics of an Electrochemical Membrane Bioreactor, Sci. Rep. 5 (2015). 